Urban Studies, Vol. 36, Nos 5-6, 1017-1027, 1999

\title{
Competitiveness and the Urban Economy: Twenty-four Large US Metropolitan Areas
}

\author{
Peter Karl Kresl and Balwant Singh
}

[Paper received in final form, October 1998]

During the past decade, as trade barriers have been lowered as a consequence of trade liberalisation negotiations conducted at both the international and the regional levels, urban economies have been increasingly vulnerable to competitive forces emanating from the most distant corners of the global economy as well as having been presented with previously unimaginable opportunities for penetration of markets equally distant. National governments have accepted self-imposed constraints on their capacity to intervene in their own economies, through adoption of limitations on the use of tariffs, quotas and other traditional devices, and through establishment of impartial, trade dispute resolution mechanisms. Technological change has only exacerbated the situation facing each urban economy and, in many industries, industrial agglomerations are giving way to plants, such as mini-mills in steel production, that can be located according to a new set of criteria-proximity to consumers and access to transport, rather than proximity to resources; or to labour with certain qualities, rather than to other firms in the same industry. In many industries, clustering, of course, remains important. The result of these two forces is the creation of new economic spaces within which new actors, urban economies, must make decisions about production and distribution; notions of periphery and centre must be rethought; and relationships of competition and co-operation take on new meaning and importance. ${ }^{1}$

This increased exposure of urban economies to economic change and rationality has made it imperative that each local government pay more attention to the competitiveness of its tradable goods industries. While they did not examine, nor do they recommend, specific policy initiatives at the level of the urban economy, Schmitz and Musyck (1994, p. 905) conclude in their study of industrial districts in Europe that:

Innovating industry, especially small industry, requires a supportive infrastructure and producer services, which the market does not necessarily deliver. In principle, these could be provided by central institutions, but they tend to be less transparent to the local user and more remote from local needs.

In our framework, this translates into a need for sub-national entities actively to be engaged in enhancement of their competitiveness.

From Adam Smith to Michael Porter, the policy literature has traditionally reserved the concept of competitiveness for the situation of individual firms or of national economies, with little or no attention being paid to the competitiveness of urban economies. Focus- 
ing solely on firms or nations when trying to improve the economic lives of working people is utterly inadequate. Ford or IBM may be very competitive as companies, but even a competitive firm will have some outmoded plants it wants to close or complete lines of product it wants to discontinue, or it may seek to enhance its competitiveness by moving production from one location to another for strategic reasons having little to do with the competitiveness of the individual locations involved. Then again, the World Economic Forum regularly counts the US as one of the world's most competitive economies, but, during the past decade or two, we have seen the economic fortunes of regions within the US, such as the 'rust belt,' the 'sun belt' or the 'upper mid-West', wax and wane with little or no correlation to what is happening to the national economy. So, especially in this era of trade liberalisation and rapid change in technology and its diffusion, we must increasingly direct our attention to the competitiveness of the urban economy, and to policies to enhance that competitiveness.

In this paper, we begin by developing a measure of the competitiveness of an individual urban economy that is both quantitative and comparative. Once this ranking of the 24 largest US Metropolitan Statistical Areas (excluding the special case of Washington, DC) according to competitiveness has been developed, the next-and equally important-task is that of explaining that ranking by means of testing of hypotheses and analysis by regression techniques. Finally, we will be in a position to describe each urban economy from the standpoint of its competitive strengths and weaknesses, in comparison with those of 23 other large US urban economies. At this point, we will be able to evaluate the city's strategic performance and planning, and even to suggest the elements that should be included in its strategic plan.

Competitiveness is not an attribute that can be measured directly; all one can do is gauge its nature and magnitude by the shadow it casts, so to speak. With this in mind, the approach taken here is that of selecting a small set of variables that can be taken as indicators of a city's competitiveness-that is, an urban economy will be competitive relative to other urban economies to the degree that its growth in these variables, during a specific period of time, exceeds, or does not, that of its 'frame of reference' urban economies. Other researchers (Peter Morici, 1988; Michael Porter, 1990; and Bruce Scott and George Lodge, 1985) have focused on the nation as the object of analysis and they all put international trade success at the centre of their analysis. International trade data for cities are not available except for the most recent years but, more importantly when urban economies are being examined, intra-national competitiveness is as important as is international competitiveness. For this reason, in our work we use the following conceptualisation:

Urban competitiveness ranking $=$ ( $\Delta$ manufacturing value added, $\Delta$ retail sales and $\Delta$ business services receipts)

The justification for use of these three variables as indicators of urban competitiveness, confirmed through relative weights by discriminant analysis, is as follows:

The growth of retail sales. Relatively rapid growth of retail sales will be a function of growth of the urban economy's population, of rising income of its inhabitants and of the degree to which it is an attractive location for non-inhabitants to visit for shopping, recreation, cultural events and dining. Again, each of these components will be indicative of competitiveness.

The growth of manufacturing value added. Relatively rapid growth of value added in manufacturing will be reflective of investments in plant and equipment, in human capital and in infrastructure. This may reflect an expansion of the manufacturing sector or a concentration on higher valued-added activities, and as such will give an indication of the overall competitiveness of the urban economy's manufacturing sector. 
The growth of business services receipts. Services are essential to any expansion of economic activity and to any transformation of economic activity. While services as a category includes several items - such as amusement, auto repair and personal services-which have little direct relation to economic competitiveness, business services expansion is reflective of an economy which is capable of restructuring itself in the contemporary context.

If the growth rate of these variables in one city is high relative to that of other cities, we argue that it is relatively competitive-that is, that it is an attractive place to make goods, to provide services and to purchase goods and services. This competitiveness may be reflected in the growth of other variables, but in ways that may be unpredictable and will be difficult to use for comparative analysis. To take one simple example, growth in a relatively competitive city may be either extensive or intensive, and population and income may increase or decrease depending on the specific circumstances to be found there. Negrey and Zickel (1994) demonstrate the complexity of the relationship between population growth and growth of manufacturing and service employment and offer a typology of six distinct relationships. So, while one might assume intuitively that competitiveness would be positively correlated with growth in population, income and/or per capita income, this is not necessarily true and we allow these variables to enter the analysis only as our empirical work shows them to be predictable and significant - that is, as explanatory rather than as indicative factors.

Our initial study (Kresl and Singh, 1995) was done for the period 1977-87, using the most recent census data available at the time; in this paper, we present an up-date of that study using the 1992 census data. Each of the variables was weighted in accordance with its share of the dollar value to the total of the three in the mid-year of the period used. For the period 1977-92, the equation used to generate the competitiveness ranking is:
Urban competitiveness ranking $=0.528$

$R S+0.388 M V A+0.084 B S R$

where, $\quad R S=$ retail sales; $\quad M V A=$ manufacturing valued added; and $B S R=$ business service receipts; with data for the growth of each during 1977-92.

In Table 1 we present our findings for the three periods. While the rankings for the longer period are of some interest, they do not differ dramatically from those of column 1 , and it is rather the marginal comparison of the base period, 1977-87, with the subsequent five years that warrants our attention. The changes in the rankings of the cities suggest at first that the major change taking place is that of a convergence towards the centre, with the highest-ranked cities during 1977-87 declining during 1987-92 and the lowest-ranked cities rising. But a closer look makes it clear that other factors were at work. For example, New York, Detroit, Los Angeles and San Diego changed by between 10 and 23 positions, but in each case these movements were the result of the collapse or resurgence of a single dominant industryfinance (New York), automobiles (Detroit) or defence (Los Angeles and San Diego). This factor has little to do with convergence.

The effects of a more powerful and more general factor are made clear in Table 2, from which it can be seen that a major determinant of the change in an urban economy's competitiveness is the region in which that urban economy happens to be located. With the exception of Cleveland, all urban economies in the Industrial Triangle and the Centre improved their competitiveness or, as with Kansas City, maintained it, while all urban economies in the North East, the Pacific Coast and the South, with the exceptions of Seattle and Tampa, experienced a loss in competitiveness. Thus it is no longer the case, as we found during 1977-87 (Kresl and Singh, 1995, p. 437), that the great regional split in the country is that of "the rust belt in decline" and "the sun belt on the rise" (although, as will be shown below, this variable does appear as a determinant of the 'engineering, research' component of the labour 


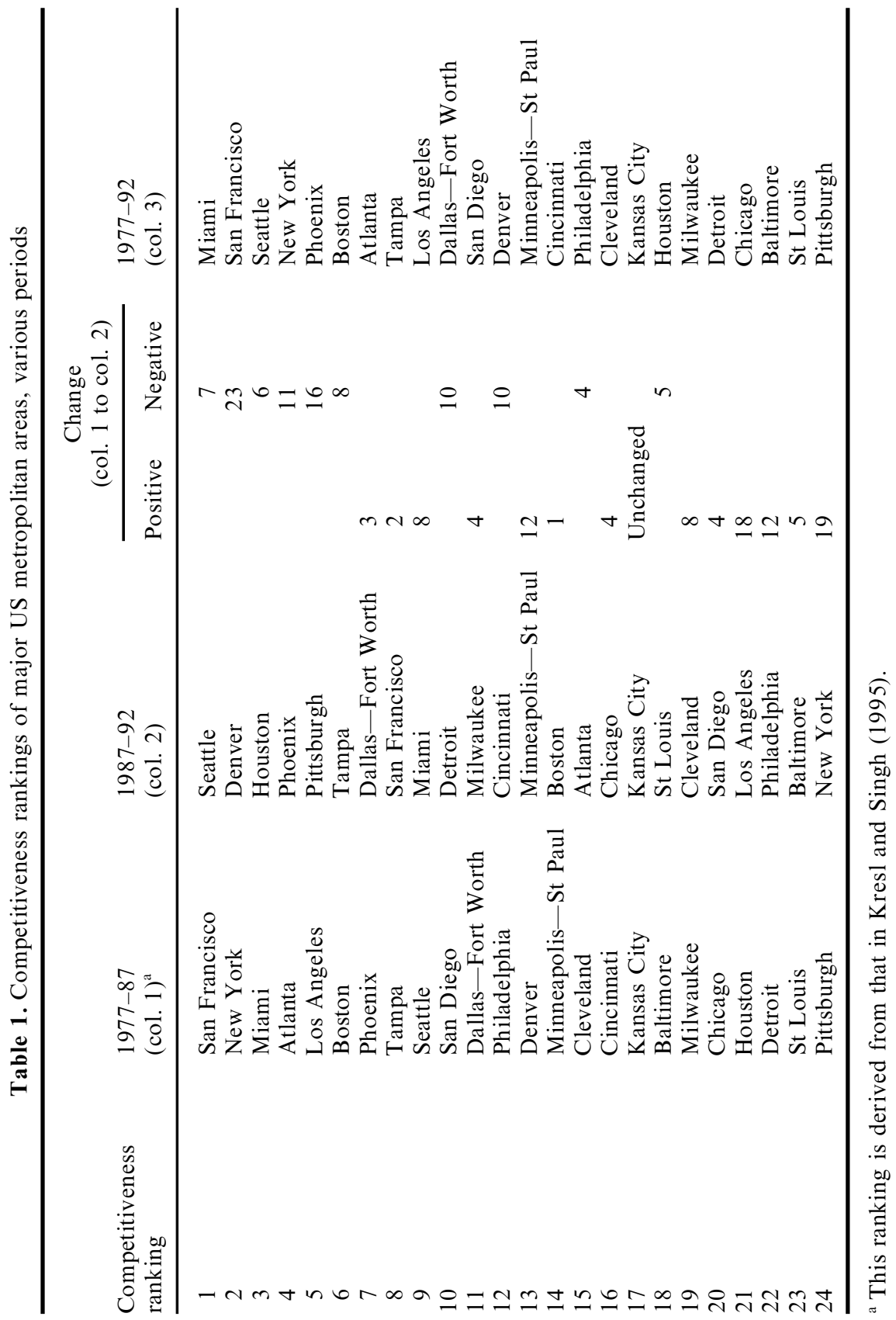


Table 2. Changes in competitiveness, major US metropolitan areas, by region, $1977-87$ and $1987-92$

\begin{tabular}{|c|c|c|}
\hline Region & Cities & Change \\
\hline \multicolumn{3}{|c|}{ The Industrial Triangle (Pittsburgh-Milwaukee-StLouis } \\
\hline & Chicago & +4 \\
\hline & Detroit & +12 \\
\hline & Cincinnati & +4 \\
\hline & Cleveland & -4 \\
\hline & Milwaukee & +8 \\
\hline & Pittsburgh & +19 \\
\hline & St Louis & +5 \\
\hline
\end{tabular}

Six of the seven metropolitan areas gained competitiveness, and one lost it. The average change was +6.86 .

The Pacific Coast

$\begin{array}{lr}\text { Los Angeles } & -16 \\ \text { San Diego } & -10 \\ \text { San Francisco } & -7 \\ \text { Seattle } & +8\end{array}$

One metropolitan area gained competitiveness, but all three California metropolitan areas lost it.

The average change was -6.25 .

The North East

$\begin{array}{lr}\text { Baltimore } & -5 \\ \text { Boston } & -8 \\ \text { New York } & -23 \\ \text { Philadelphia } & -10\end{array}$

All four metropolitan areas lost competitiveness.

The average change was -11.50 .

The South

$\begin{array}{lr}\text { Atlanta } & -11 \\ \text { Miami } & -6 \\ \text { Tampa } & +2\end{array}$

Two metropolitan areas lost competitiveness, and one gained it. The average change was -5 .

The Centre

$\begin{array}{lc}\text { Dallas_Fort Worth } & +4 \\ \text { Denver } & +12 \\ \text { Kansas City } & \text { Unchanged } \\ \text { Minneapolis_St Paul } & +1 \\ \text { Phoenix } & +3\end{array}$

No metropolitan area lost competitiveness; four retained it and one was unchanged.

The average change was +4.00 .

force); rather, it is a somewhat more complex picture of regional rise and decline. The facts that some urban economies bucked the trend and that the rates of gain or loss within a region differ dramatically suggest that other factors dominate the changes in urban competitiveness we have observed.

These regional advances and retreats are 


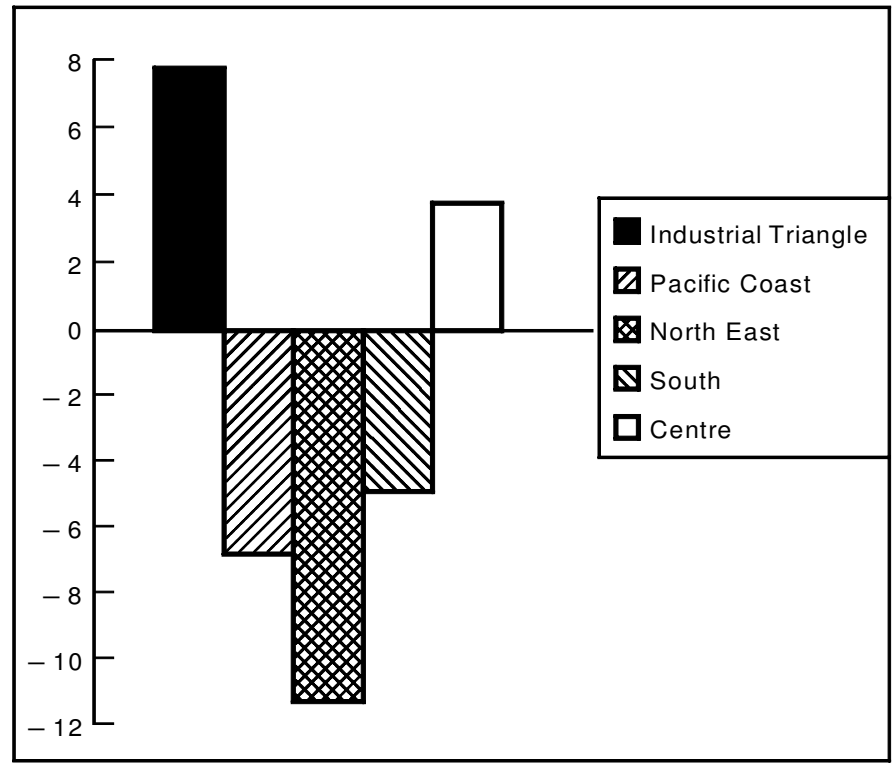

Figure 1. Regional winners and losers: changes in competitiveness ranking, between $1977-87$ and 1987-92.

presented in summary form in Figure 1. The competitiveness rankings of major US cities, interesting in themselves though they are, provide us with the basis for a far more important exercise-that of explaining the rankings. That is, why is it that city ' $x$ ' is ranked as it is and why is it higher or lower than city ' $y$ '? We have just argued that changes in manufacturing value added, in retail sales and in service-sector receipts could serve as indicators of an urban economy's relative competitiveness; now we need another set of variables that will explain the ranking and will also give us a tool for evaluating an urban economy's economic development strategy to date and for designing a strategy that will build on a city's strengths and weaknesses - in comparison with other urban economies with which it is in competition for plant locations, decision-making centres and financial and other service facilities - and thus enable the urban economy to realise its true potential.

In order to gain some guidance in the selection of variables to explain urban competitiveness and to provide an understanding of the specific relation between the two, a survey of the literature was conducted (see Kresl 1995). From that, we get the following general conceptualisation: urban competitiveness is determined by both economic determinants and strategic determinants. The economic determinants are composed of factors of production, infrastructure, location, economic structure and urban amenities; and the strategic determinants are composed of governmental effectiveness, urban strategy, public-private sector co-operation and institutional flexibility. While the economic determinants are quantitative in nature and data for them can be gained from a variety of statistical sources, the strategic determinants are qualitative in nature and can be got only through interviews and examination of the relevant local documents. We have not yet been able to compile the latter material, as the response from mayors' offices to our request for information was not complete. However, we are able to present the analysis of the economic determinants of urban competitiveness and do so with equation (2). (See Table A1 for the analysis of variance.) 


$$
\begin{aligned}
U C= & -10.8+3.41 x^{1}+0.0112 x^{2} \\
& +4.24 x^{3}-0.00175 x^{4}+0.594 x^{5} \\
& +0.288 x^{6}+0.513 x^{7}+0.000094 x^{8}
\end{aligned}
$$

$t-3.10 \quad 1.882 .08 \quad 1.93 \quad-2.47 \quad 1.73 \quad 1.73$

1.943 .38

p 0.0070 .0800 .0550 .0730 .0261 .041 .05

0.0710 .004

$R^{2} 76.5$ per cent $R^{2}$ (adjusted) 64.0 per cent

where, $\quad U C=$ urban $\quad$ competitiveness; $x^{1}=$ growth in per capita money income, 1979-87; $x^{2}=$ Research centres/MVA, 1987; $x^{3}=$ growth in the percentage of firms with more than 100 employees, 1977-82; $x^{4}=$ number in labour force with more than BA/BS, $1990 ; x^{5}=$ share of EARM workers in total labour force, $1987 ; x^{6}=$ growth in number of cultural institutions, 1981-93; $x^{7}=$ growth in the capital stock for the state, 1977-85; and $x^{8}=$ exports as a share of total output, 1993.

Eight 'primary' variables are used to explain the competitiveness ranking. Each is in conformity with what would be expected from a reading of the literature, and each is significant at the 0.10 or lower level of confidence. Some of these variables are very straightforward and require no further explanation, but we have done further analysis to explain the 'engineering, administrative, research and management' component of the labour force and the growth in per capita income.

Equations (3) and (4) present our findings, which add another eight 'secondary' variables which explain these two of the explanatory elements of equation (2). Each of these variables is significant at the 0.05 level of confidence.

In any empirical analysis, we are of course constrained by the statistical series that are available in identical format for all of the urban economies and by the years for which the series are published. For example, the urban economy export data were not available prior to 1993. If the relative positions of the urban economies change significantly over time, then 1993 data would not be all that relevant for a study of the years 1977 92. However, a recent paper by Noponen et al. (1997) concludes that "cities have different stakes in national trade policy as a result of their unique structural situations" (p. 75) and that "metropolitan areas across the United States are quite differentially positioned to benefit from greater international market integration" (p. 67). Their references to "unique structural situations" and to "differentially positioned" suggest that relative export performance probably does not vary significantly over shorter periods of time and that use of the 1993 data is legitimate.

In several specifications of the variable relating to the educational level of the labour force (see equation (3) and Table A2), we consistently found a negative correlation with competitiveness, but the sum of the squares explained by this variable is very small. This could be a reflection of the high degree of mobility of the highly educated component of the labour force-certain activities attract educated workers to urban economies without regard to the educational attainment of the resident population.

$$
\begin{gathered}
E A R M / N=-1.29+2.41 x^{9}+0.000058 x^{10} \\
+2.54 x^{11}+0.477 x^{12}
\end{gathered}
$$

$R^{2} 73.6$ per cent $R^{2}$ (adjusted) 68.0 per cent where, $E A R M / N=$ share of EARM workers in total labour force, $1987 ; x^{9}=$ growth in population, $1980-90 ; \quad x^{10}=$ transport services; $x^{11}=$ research centres/labour force, 1987; and $x^{12}=$ location in the sun belt.

Culture is taken to be a proxy for 'urban amenities'-historical districts, galleries, performance centres, good restaurants and so forth. Given the importance of New York as a centre of culture, it should be no surprise that this urban economy has studied the impacts of culture activity on its economy more than has any other urban economy. In 1993, the Port Authority of New York and New Jersey issued a report which detailed the enormous impact of culture and the arts on 
employment and incomes in the New York metropolitan region; a second report has just been compiled by McKinsey and Company (see Lyman, 1997). Both stress the linkages between the arts and the business community and New York's reliance on creative activities. Our results validate the hypothesis that the growth of cultural institutions is a contributory factor in an urban economy's competitiveness and that the absolute number of cultural institutions is important in the growth of per capita income (see equation (4); and Table A3 for analysis of variance). We suggest that the latter impact reflects the insistence of high-skill professionals and executives that they and their families must live in proximity to culture and the arts.

$$
\begin{aligned}
& \$ Y 87 / 79=0.466+0.00353 x^{13}+0.0183 x^{14} \\
& +0.265 x^{15}+0.00476 x^{16} \\
& t 1.522 .353 .103 .192 .29 \\
& \text { p } 0.1460 .0300 .0060 .0050 .033
\end{aligned}
$$$$
R^{2} 47.9 \text { per cent } R^{2} \text { (adjusted) } 37.0 \text { per }
$$$$
\text { cent }
$$

where, $\$ Y 87 / 79=$ growth in per capita money income, $1979-87 ; x^{13}=$ fiscal, regulatory and political climate; $\mathrm{x}^{14}=$ percentage of firms with more than 20 employees, 1980; $\mathrm{x}^{15}=$ growth in the labour force, 1979-87; and $\mathrm{x}^{16}=$ number of cultural institutions, 1981 .

If this analysis is to be of much use to the individual city in designing a policy response to the need to enhance its competitiveness, the information gained from equations (2), (3) and (4) must be presented in a way that is of use to decision-makers in designing a strategy for enhancement of the urban economy's competitiveness. This has been done in Table 3. In the first column, the metropolitan areas are arrayed from the most (Miami) to least (Pittsburgh) competitive for the period 1977-92. Representatives of individual cities will rightly argue that much has happened in their urban economy during the ensuing five years; the figures in columns 1, 2 and 3 of Table 1, above, do indicate that many changes have taken place between 1987 and 1992. Nonetheless, our interest here is in gaining an insight into the variables that over the longer run explain an urban economy's competitiveness relative to that of other urban economies-hence our use of the period 1977-92 in this section of the paper. Across the top of Table 3 are listed the primary determinants and secondary determinants of urban competitiveness. The comparative strengths and weaknesses of a metropolitan area can be discovered by reading across the table in the appropriate row. For example, Denver, ranked 12th overall, is rated very highly (ranked above 12th) in research centres (both when related to manufacturing value added and to the labour force), in the 'engineering, research' (EARM) component of the labour force and in the growth of its cultural institutions. However, its weaknesses (ranked below 12 th) are in the growth of per capita income, capital investment in the state, share of output that is exported, the share of firms with 20 or more employees, growth of the labour force during 1977-87 and the number of its cultural institutions. If the leadership of Denver wishes to enhance its competitiveness, any strategic plan should take into account the urban economy's comparative strengths and weaknesses. This exercise could be repeated for any of the other urban economies in the study.

The individual metropolitan area does not, of course, have control over all of the primary and secondary determinants which have been identified as important for urban competitiveness, but it does have a strong impact on some-for example, its cultural and educational institutions-and, working with state or national government, most of the rest can be improved. This suggests the importance of the qualitative 'strategic determinants', such as the effectiveness of local governance and public-private sector cooperation, which have not been included in this quantitative analysis.

The obvious advantage of the approach we suggest here is that the leadership of a metropolitan area can get an empirically based, objective understanding of their competitive advantages and disadvantages and that urban 


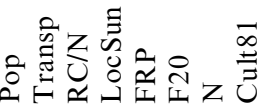

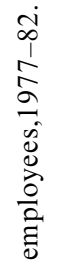

○̊․ㅇ

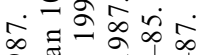

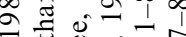
问远 웜

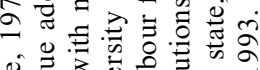

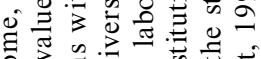

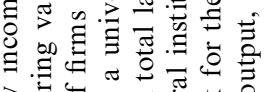

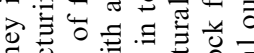

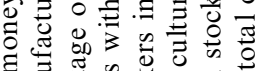

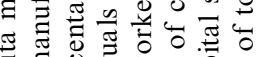

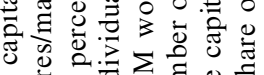

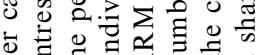

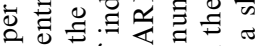

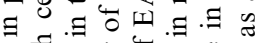

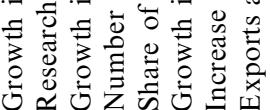

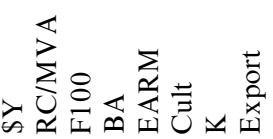


economy can be evaluated relative to other urban economies, presumably with which it is in competition for the location of various sorts of economic activity. The city may be proud of a new concert hall, but if all other cities have also built new concert halls there is no competitive advantage in having one; having one is simply the price of staying in the game.

In this paper, we have shown how the concept of competitiveness, traditionally reserved for use with either national economies or firms, has relevance to urban economies and how practitioners and/or leaders in the metropolitan area can use this concept to guide the evolution of their individual local economies. ${ }^{2}$ We have argued that this can be done most effectively if the approach taken is one that is both empirical and comparative. The government of a metropolitan area can ascertain that urban economy's competitive position in relation to other, competing urban economies and it can also discover that urban economy's comparative strengths and weakness, using a relatively objective methodology. We have also, through regression analysis and analysis of variance, discovered which of the factors discussed in the research literature and in the popular press actually are important in the determination of an urban economy's competitive position. Finally, we have shown how a metropolitan area's leadership can use all of this information when it comes to evaluating its past planning performance and to designing a strategic plan for the competitiveness enhancement of that urban economy.

Trade liberalisation and technological change have caused the economic globalisation that is so frequently discussed today. Local leaders certainly recognise that the context in which their decision-making takes place, their position relative to the national government and the importance and urgency that attach to their decision-making have all been drastically altered by globalisation. Urban economies that get their decision-making right are likely to have futures characterised by more attractive employment opportunities, rising incomes, growing tax revenues to fund the array of demands for social, educational and infrastructure projects with which they are being confronted, and social stability; those that do not act firmly and with wisdom are likely to suffer marginalisation, declining economic conditions and social tensions.

\section{Notes}

1. Purely for stylistic purposes, throughout this text we will use the words city, metropolitan area and urban economy to refer to the object of our empirical analysis, the metropolitan statistical area (PMSA or MSA).

2. In this paper, we used data for MSAs in the US, primarily because it is easy to get comparable data for a large number of cities. The phenomenon analysed here has equal relevance for urban economies in Canada, Japan and the European Union, as well as for those in Africa, Asia and Latin America; the difficulty in applying this approach to these other urban economies is, of course, the problem of obtaining suitable data. This methodology is currently being applied to a more comprehensive set of cities in Canada and the US. If data problems can ever be surmounted, an application to cities of the EU would be an obvious next step.

\section{References}

Kresl, P. K. (1995) The determinants of urban competitiveness: a survey, in: P. K. KRESL and G. GAPPERT (Eds), North American Cities and the Global Economy, pp. 45-68. Thousand Oaks, CA: Sage Publications.

Kresl, P. K. and Singh, B. (1995) The competitiveness of cities: the United States, in: OECD (Ed.) Cities and the New Global Economy, pp. 424-446. Melbourne: The Government of Australia and the OECD.

LyMAN, R. (1997) Finding government profit in aid to the arts, The New York Times, 16 July, p. $\mathrm{B} 1: 3$.

Morici, P. (1988) Reassessing American Competitiveness. Washington, DC: National Planning Association.

Negrey, C. and Zickel, M. B. (1994) Industrial shifts and uneven development: patterns of growth and decline in U.S. metropolitan areas, Urban Affairs Quarterly, 30(1), pp. 27-47.

Noponen, H., Markusen, A. and Driessen, K. (1997) Trade and American cities: who has the comparative advantage?, Economic Development Quarterly, 11(February), pp. 67-87.

Port Authority of New York and New Jersey 
(1993) The arts as an industry: their economic importance to the New York-New Jersey Metropolitan Region. Port Authority of New York and New Jersey, October.

Porter, M. (1990) The Competitive Advantage of Nations. New York: The Free Press.

Schmitz, H. and Musyck, B. (1994) Industrial districts in Europe: policy lessons for developing countries?, World Development, 22(6), pp. 889-910.

Scott, B. and Lodge, G. C. (Eds) (1985) U.S. Competitiveness in the World Economy. Boston, MA: Harvard Business School Press.

\section{Appendix}

Table A1. The analysis of variance for equation (2)

\begin{tabular}{lrcccc}
\hline Source & DF & SS & MS & $F$ & p \\
\hline Regression & 8 & 17.0095 & 2.1262 & 6.811 & 0.001 \\
Error & 15 & 5.72200 & 0.3480 & & \\
Total & 23 & 22.2295 & & & \\
$x^{1}$ & 1 & 2.2188 & & & \\
$x^{2}$ & 1 & 1.5037 & & & \\
$x^{3}$ & 1 & 3.8035 & & & \\
$x^{4}$ & 1 & 0.0044 & & & \\
$x^{5}$ & 1 & 5.7296 & & & \\
$x^{6}$ & 1 & 0.2134 & & & \\
$x^{7}$ & 1 & 0.6104 & & & \\
$x^{8}$ & 1 & 2.9257 & & \\
\hline
\end{tabular}

Table A2. The analysis of variance for equation (3)

\begin{tabular}{lrcccc}
\hline Source & DF & SS & MS & $F$ & p \\
\hline Regression & 4 & 6.1415 & 1.5354 & 13.24 & 0.000 \\
Error & 19 & 2.2034 & & & \\
Total & 23 & 8.3449 & & & \\
$x^{9}$ & 1 & 3.6476 & & & \\
$x^{10}$ & 1 & 0.7866 & & & \\
$x^{11}$ & 1 & 1.1659 & & & \\
$x^{12}$ & 1 & 0.5413 & & & \\
\hline
\end{tabular}

Table A3. The analysis of variance for equation (4)

\begin{tabular}{lrcccc}
\hline Source & DF & SS & MS & $F$ & p \\
\hline Regression & 4 & 0.165639 & 0.041410 & 4.37 & 0.011 \\
Error & 19 & 0.179893 & 0.009468 & & \\
Total & 23 & 0.345532 & & & \\
$x^{13}$ & 1 & 0.031200 & & & \\
$x^{14}$ & 1 & 0.008568 & & & \\
$x^{15}$ & 1 & 0.076024 & & & \\
$x^{16}$ & 1 & 0.049847 & & & \\
\hline
\end{tabular}


Copyright of Urban Studies is the property of Carfax Publishing Company and its content may not be copied or emailed to multiple sites or posted to a listserv without the copyright holder's express written permission. However, users may print, download, or email articles for individual use. 